\title{
ANTICOAGULATION MONITORED BY NURSING CONSULTATIONS: THROMBOEMBOLISM AND DYSCRASIA - PROSPECTIVE COHORT
}

Maria Cecilia Pereira Bosa 1, Dalmo Valério Machado de Lima 2, Fatima Helena do Espírito Santo 2, Ana Carolina Gurgel Câmara 1, Paula Dias Vidigal 2, Fernanda Faria Reis 2

\author{
1 Federal University of Rio de Janeiro \\ 2 Fluminense Federal University
}

\begin{abstract}
Observational study, prospective cohort type with quantitative approach for occurrence analysis of hemorrhagic and thromboembolism outcomes on cardiopath patients carriers of metallic mechanical valves or chronic atrial fibrillation with warfarin in use, accompanied at an oral anticoagulation ambulatory of a Cardiology Institute in Rio de Janeiro City. Objective: Evaluate the impact of orientations from Nursing Consultation as the occurrence of thrombotic or hemorrhagic effects. Method: Prospective nonprobabilistic cohort sample of limited convenience to the temporal cutting between August 2011 and February 2012. The data treatment will be based on descriptive statistics and risk calculation for analysis of correlated variables: International Normalized Ratio, hemorrhagic and thromboembolism events.

Descriptors: Nursing Care; Valve Protesis; Atrial Fibrillation; Warfarin; International Normalized Ratio.
\end{abstract}

\section{THEMATIC CONTEXTUALIZATION ANDRESEARCH PROBLEM}

The non-contagious chronic diseases, such as cardiac and cerebrovascular diseases, diabetes and cancer, count as two-thirds of all deaths in the world, due to population aging and spreading of risk factors, associated to globalization and urbanization. The control of risk factors like smoking, sedentarism, poor diet and excessive consumption of alcohol gets more and more critical. The World Health Organization reported that about four in ten men, and one in eleven women smoke, and about one in eight adults is obese $^{(1)}$.

In Brazil, cardiovascular diseases are the cause of the higher quantities of deaths since 1960, and 25 millions are estimated for 2020. Atrial fibrillation is the most common cardiac arrhythmia in clinical practice, very often on chronic pneumopathies, reaching one-fourth of all carriers of cardiac insufficiency. It's a supraventricular tachyarrhythmia, 
responsible for one-third of hospitalizations, with prevalence of $1 \%$ to $2 \%$ on general population. On the other hand, the valve diseases, being stenotics, regurgitants or mixed diseases, reach the younger population. As much in carriers of $A F$, as in patients submitted to valve changes, the anticoagulation is indicated, and clear protection of the patient against thromboembolic events ${ }^{(2)}$. Sodium warfarin, nowadays, is the most used drug in oral anticoagulation therapy for many reasons: low cost, easier access for public network and important effetcs on prothrombin activation. However, due to uncountable factors that interfere in its availability, it's a hard control drug. New drugs, offering lower interaction with other substances, like Dabigatran, await market release. The International Normalized Ratio (INR) is a measure embraced by World Health Organization to globally standardize the result of Prothrombin Activity time test and it has been effective on anticoagulation monitoring. The great interest in this subject came from an ascertainment by the researcher of aggravating factors and clinical occurrences generated by lack of orientations about oral anticoagulation therapy. The monitoring of the factors that contribute for INR maintenance inside the target is really important, because it helps on identifying aspects of a better health and life conditions ${ }^{(3)}$. The study is significant to practice, as far as it bases its actions. To research, for identifying nurse insertion areas and; for education, once it can be incorporated to the profession regular curricula.

\section{OBJECTIVES}

Overview: Identify the risk factors and protection seen on patients using sodium warfarin and carriers of atrial fibrillation and/or mechanical valve, to the INR changes and under occurrence of thrombotic and hemorrhagic events.

\section{Specifics:}

- Identify the association between complications for using oral anticoagulation therapy (OAT) and possible factor like adhesion and comprehension;

- Evaluate the effectiveness of nursing interventions on educational process of patients using OAT. 


\section{METHODOLOGY}

Observational study, prospective cohort type with quantitative approach for occurrence analysis of thromboembolism and hemorrhagic outcomes on cardiopath patients carriers of metallic mechanical valves and/or chronic atrial fibrillation with sodium warfarin in use. The target population will be formed by accompanied patients at an oral anticoagulation ambulatory of the Cardiology National Institute, in Rio de Janeiro City. It's about a prospective non-probabilistic cohort sample of limited convenience to the temporal cutting between August 2011 and February 2012. Inclusion criteria: atrial fibrillation carrier and/or with metallic valves and using sodium warfarin, accompanied since second consultation at the ambulatory, aged 18 or older who wants to participate of the trial through Informed Consent Form. Exclusion criteria: suspension or interruption of anticoagulant under medical orders, carriers of serious hepatic diseases or oncologic diseases treated by chemotherapy. The documentary analysis happens on the institutional database: name, age, gender, address, schooling, business activity, familiar income and medical diagnosis. Two questionnaires will be applied: the first contains 15 open and closed questions based on orientations in the "oral anticoagulation guide"; the second contains 8 open and closed questions that evaluate, in each return, modification of NIR, signals and hemorrhagic or thrombotic symptoms and habits of life. The treatment of data happens by descriptive statistic with measures of central tendency, dispersion, relating risk calculation and tests of association by chi-square or Fisher. Significance level of $5 \%$.

\section{REFERENCES}

1. Organização Mundial de Saúde. Novo Relatório da OMS sobre Estatísticas de Saúde no Mundo. [Maio/2011]. Available at www.onu.org.br/novo-relatório-da-omstraz-informações-sobre-estatísticas-de saúde-em-todo-o-mundo/

2. Woods S, Froelicher E, Motzer S. Enfermagem em Cardiologia. São Paulo, 2005.p.4678.

3. Stipp MAC, Cunha NM. Risco Cardiovascular numa clientela ambulatorial - Um estudo quantitativo. Online Braz J Nurs [online] 2008 jan; [mentioned in August 16, 2011]; 3(0).Available at: http:www.objnursing.uff.br/index.php/nursing/article/view/j.

$\underline{676-4285.2008 .1213 / 2 .}$ 


\section{PROJECT DATA}

Project data: Dissertation project for Assistencial Nursing Professional Master Degree Program, approved by the Ethics Committee in Research, Cardiology National Institute $\mathrm{n}^{\circ}$ 0341/21-06-2011

Mailing address: Rua Esteves Júnior 39/ 501 - Laranjeiras RJ CEP 22231-160 